\title{
The Impact of Cyclic Prefix on Capacity for LTE-A Using Open Loop Spatial Multiplexing
}

\author{
Emad Aldeen Abd Allah Omer ${ }^{1}$, Mohammed Abakrer Hussian² \\ ${ }^{1}$ Alneelain University, Faculty of engineering, Aljamhorya Road, Khartoum, Sudan \\ Emadmaster11[at]gmail.com \\ ${ }^{2}$ Alneelain University, Faculty of engineering, Albaladya Road, Khartoum, Sudan \\ abaker2826022[at]yahoo.com
}

\begin{abstract}
The Permanent need for increasing data rates has made the use of multiple input multiple output and orthogonal frequency division multiplexing is useful in fourth-generation networks, but some of these techniques give a reduction in the level of data transfer. The use of orthogonal frequency division multiplexing (OFDM) system for LTE depends on cyclic prefix (CP) to avoid inter-symbol and inter-carrier interference, however it is not introduce Increase system capacity, and it is wasting channel resources. In this paper, we will evaluate the impact of cyclic prefix on system capacity for two approaches, in first approach, we evaluate capacity with normal cyclic prefix and in second approach we tack the evaluation with extended cyclic prefix and make brief comparison between the two approaches. The study results show that Optimization of the signal -to-noise ratio and improve the system by increasing the number of antennas at the transmitter in Open Loop Spatial Multiplexing increases the system capacity, Finally we made a comparison between the normal cyclic prefix and extended cyclic prefix the result show that normal cyclic is better to increase the system capacity.
\end{abstract}

Keywords: cyclic prefix, LTE, MIMO, OLSM

\section{Introduction}

The long term evolution Introduced new techniques to increase the data rate and reduce delay and Interference those techniques such as Orthogonal frequency division multiplexing, MIMO, transmit diversity, spatial multiplexing and cyclic prefix[1]. Despite the benefits of those technologies, but it had a negative effect on the performance of the system, because it adds more of a burden on the system and the objective of this study was to identify the cyclic prefix effect on capacity of the system.

The multiplicity of paths between sender and receiver and the obstacles such as buildings, trees and mountains generate a kind of delay that is called delay spread each signal have delay depends on the path between the transmitter and receiver so the faster signals in access is direct line-of-sight path signal.

A synchronizing process between the different delay spread component performed and adjusting their individual timings by the system before combining them but that typically in the time domain receiver, in LTE no need for this process because it operate on aggregate received signal directly.

To provide protection against multi- path delay the LTE system uses a cyclic prefix to make a guard period at the beginning of each OFDMA symbol [2].

To ensure efficiency the duration of the multi-path delay spread must be less than the duration of the cyclic prefix, the signal Suffer from low delay spread durations and high delay spread durations so LTE uses the normal cyclic prefix for the first scenario and the extended cyclic prefix for the last one.

This [3] table show cyclic prefix types
Table 1: Cyclic prefix types

\begin{tabular}{|c|c|c|c|c|}
\hline & \multicolumn{2}{|c|}{ Normal Cyclic Prefix } & \multicolumn{2}{c|}{$\begin{array}{c}\text { Extended Cyclic } \\
\text { Prefix }\end{array}$} \\
\hline & \multicolumn{2}{|c|}{$15 \mathrm{kHz}$ subcarriers } & $\begin{array}{c}15 \mathrm{kHz} \\
\text { subcarri } \\
\text { ers }\end{array}$ & $\begin{array}{c}7.5 \mathrm{kHz} \\
\text { subcarriers }\end{array}$ \\
\hline & $160 \mathrm{Ts}$ & $144 \mathrm{Ts}$ & $512 \mathrm{Ts}$ & $1024 \mathrm{Ts}$ \\
\hline Duration & $\begin{array}{c}5.2 \mathrm{micro} \\
\mathrm{s}\end{array}$ & 4.7 micro s & $\begin{array}{c}16.7 \\
\text { micro s }\end{array}$ & $\begin{array}{c}33.3 \text { micro } \\
\mathrm{s}\end{array}$ \\
\hline $\begin{array}{c}\text { Equivalent } \\
\text { Distance }\end{array}$ & $1.6 \mathrm{~km}$ & $1.4 \mathrm{~km}$ & $5 \mathrm{~km}$ & $10 \mathrm{~km}$ \\
\hline Overhead & $\begin{array}{c}160 / \\
2048=\end{array}$ & $\begin{array}{c}144 / 2048 \\
=7.0 \%\end{array}$ & $\begin{array}{c}512 / \\
2048= \\
25 \%\end{array}$ & $\begin{array}{c}1024 / \\
4096=25 \\
\%\end{array}$ \\
\hline
\end{tabular}

Next figure 1 represents the process of cyclic prefix:

The system Copies end of the main part of the OFDMA symbol to use it to create the cyclic prefix as shown in figure 1

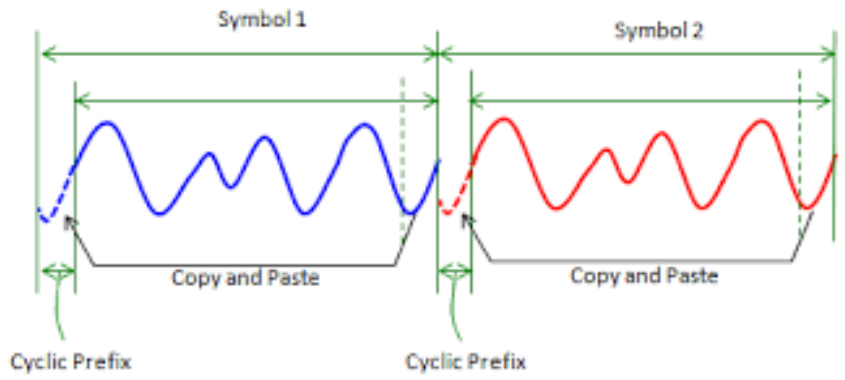

Figure 1: Cyclic prefix

\section{System Model}

A capacity study for the third LTE downlink transmission mode the open loop spatial multiplexing (OLSM 4X2) for case in $(25,30,35,40$, and 100$) \mathrm{MHz}$ will be presented, the 


\section{International Journal of Science and Research (IJSR) \\ ISSN (Online): 2319-7064 \\ Index Copernicus Value (2013): 6.14 | Impact Factor (2015): 6.391}

capacity calculations will be performed by two different approaches, the first approach takes into account the effect of the normal cyclic prefix, while the other approach takes into account the effect extended cyclic prefix and explain the differences.

2.1 The general capacity equation: [4]

$$
C=w \log _{2}\left(1+\frac{S}{N}\right)
$$

Where SNR is the signal to noise ratio and $\mathrm{W}$ is the effective bandwidth.

2.2 Capacity with correction factor: [5]

$$
C=F * B \log _{2}(1+S N R)
$$

Where SNR is the signal to noise ratio, B is the effective band width $\mathrm{F}$ is the correction factor.

2.3 Effective band width[5]

$\mathrm{e} B=\frac{N_{S c} * N_{S} * N_{r b}}{T_{S u b}}$

Where $\mathrm{N}_{\mathrm{sc}}=12$ is the subcarriers in one $\mathrm{RB}, \mathrm{N}_{\mathrm{s}}$ is the number of OFDM symbols in one subframe (14 for normal Cyclic Prefix (CP) and 12 for extended cyclic prefix ), $\mathrm{N}_{\mathrm{rb}}$ is resource block that fit into the selected system bandwidth (for example $6 \mathrm{RBs}$ within a $1.4 \mathrm{MHz}$ system bandwidth) and $\mathrm{T}_{\text {sub }}$ is the duration of one subframe equal to $1 \mathrm{~ms}$. As it is illustrated in figure 2.6.

In one slot for normal cyclic prefix, the length of the first symbol is 5.2 microseconds while for the other six symbols the length is 4.7 microseconds, while for extended cyclic prefix the six symbols have the same length of 16.7 microseconds.

2.4 Correction factor: [5]

$F=\frac{T_{\text {frame }}-T_{c p}}{T_{\text {frame }}} * \frac{N_{s c} * N_{s} / 2-R}{N_{s C} * N_{s} / 2}$

The first part of the above equation represents the cyclic prefix loss in which $\mathrm{T}_{\text {frame }}$ is the fixed frame duration equal to $10 \mathrm{~ms}$, And $\mathrm{T}_{\mathrm{cp}}$ is the total CP time of all OFDM symbols within one frame, And the second part represents the reference symbols loss where $\mathrm{R}$ is the number of resource elements (RE) that carries the reference symbols in the antenna port (Reference Signal) (R) is provided to enable the user equipment (UE) to estimate the radio channel).

\subsection{LTE Transmission mode 3: open-loop spatial multiplexing (OLSM 4X2)}

Several data streams are transmitted over different parallel channels provided by the multiple transmit and receive antennas, figure 2 shows $4 \mathrm{X} 2$ MIMO.

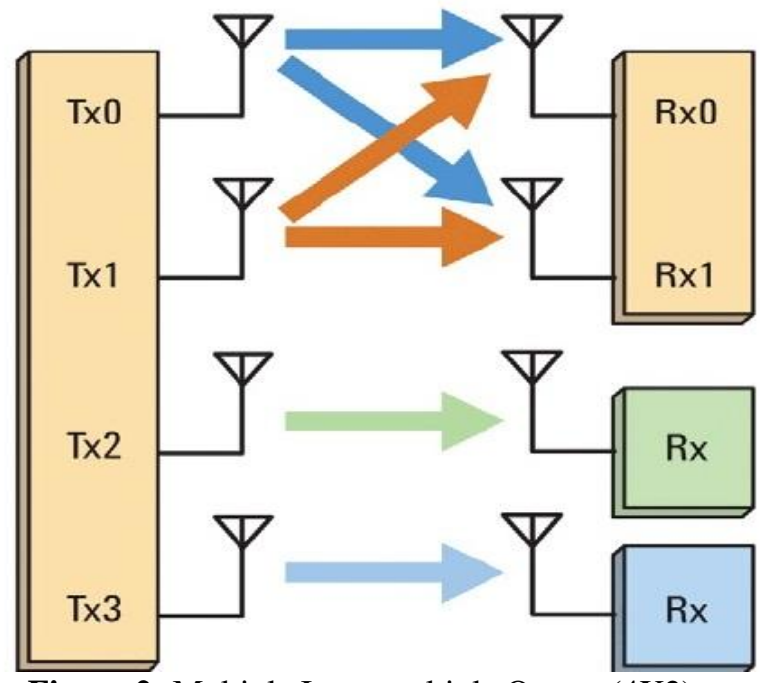

Figure 2: Multiple Input multiple Output (4X2)

The capacity for the first approach is: [5]

$$
C=\min \left(N_{T}, N_{R}\right) * F * B \log _{2}(1+S N R)
$$

Where $\min \left(\mathrm{N}_{\mathrm{T}}, \mathrm{NR}\right)$ is the minimum number of the transmitting and receiving antennas.

\section{Simulation Result}

MATLAB tools have been used for evaluate the capacity. The figures (3to 7) below show the comparison of output curves between Signal to Noise Ratio (SNR) and capacity by the normal cyclic prefix and the extended cyclic prefix by using 4 number of transmit antenna (4), it is obviously normal cyclic prefix has better results than extended cyclic prefix and the capacity is proportional to the bandwidth.

\subsection{Figures of capacity comparison:}

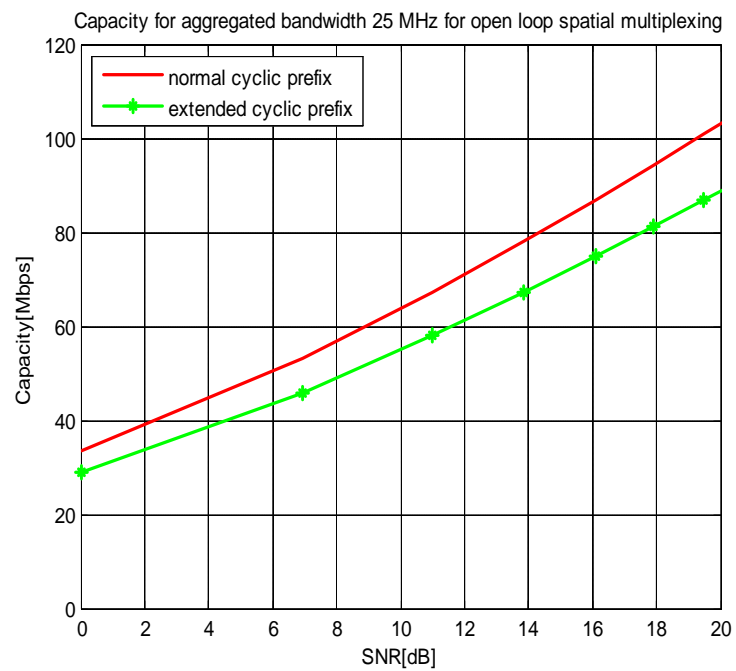

Figure 3: Capacity comparison for normal cyclic prefix and the extended cyclic prefix in $25 \mathrm{MHz}$. 


\section{International Journal of Science and Research (IJSR) \\ ISSN (Online): 2319-7064 \\ Index Copernicus Value (2013): 6.14 | Impact Factor (2015): 6.391}

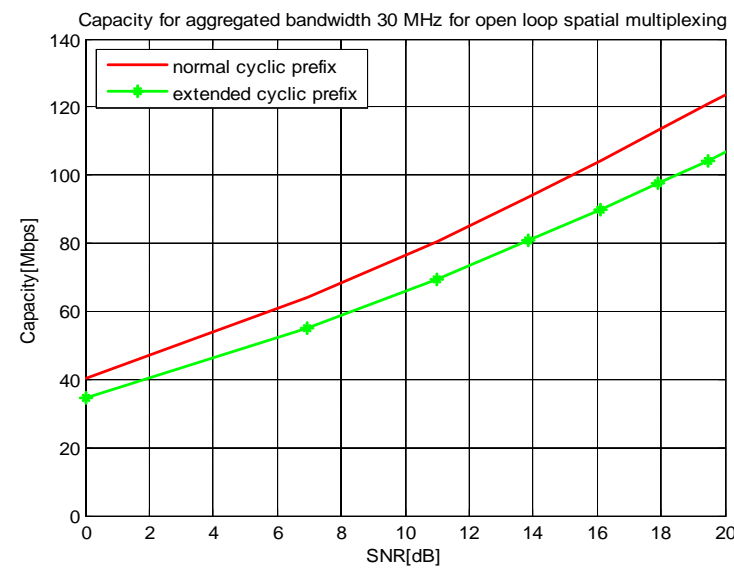

Figure 4: Capacity comparison for normal cyclic prefix and the extended cyclic prefix in $30 \mathrm{MHz}$.

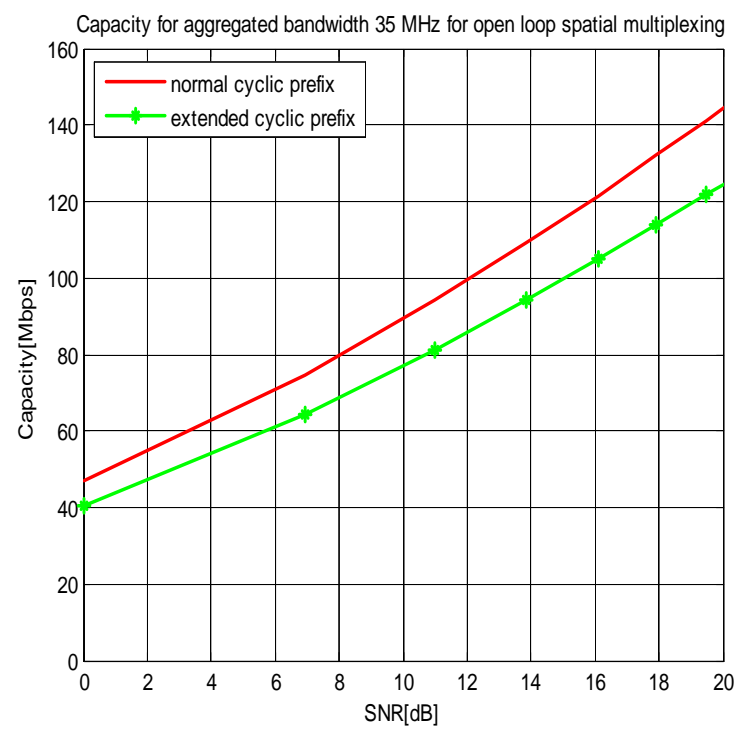

Figure 5: Capacity comparison for normal cyclic prefix and the extended cyclic prefix in $35 \mathrm{MHz}$.

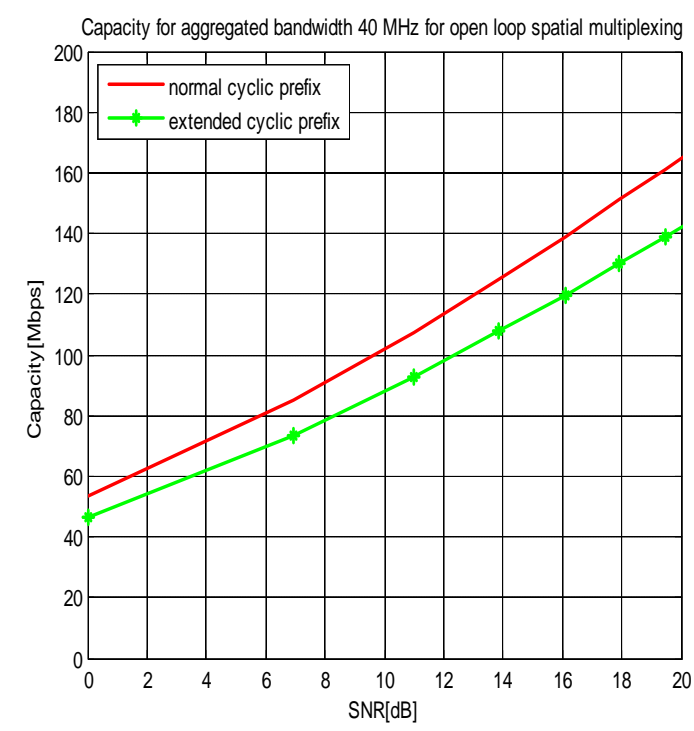

Figure 6: Capacity comparison for normal cyclic prefix and the extended cyclic prefix in $40 \mathrm{MHz}$.

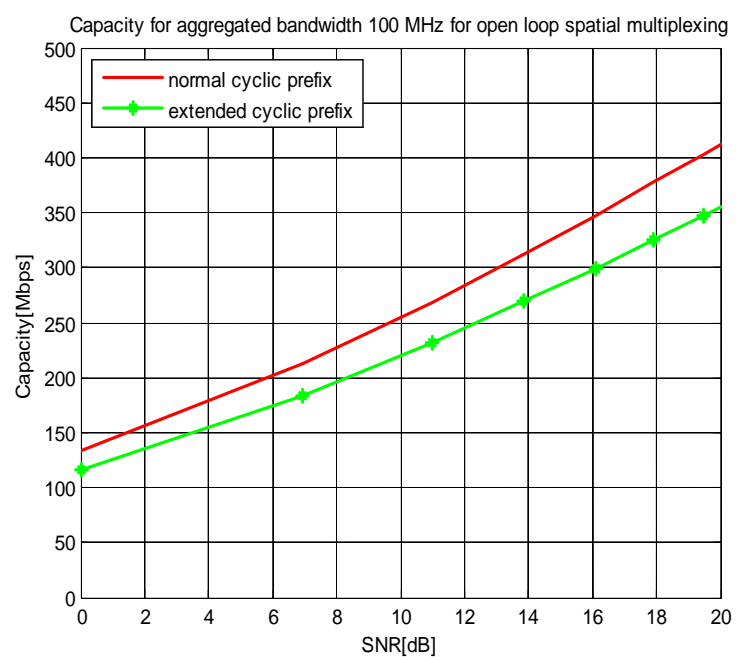

Figure 7: Capacity comparison for normal cyclic prefix and the extended cyclic prefix in $100 \mathrm{MHz}$.

3.2 Table 2 gives the numerical values of capacity comparison in Mbps for normal cyclic prefix and extended cyclic prefix in all bandwidth.

\begin{tabular}{|l|l|}
\hline cyclic prefix & \multicolumn{1}{|c|}{ capacity at SNR 19.46 dB } \\
\hline $\mathbf{2 5} \mathbf{~ M H z}$ & 100.8 \\
\hline normal cyclic prefix & 86.94 \\
\hline Extended cyclic prefix & $13.86 \mathrm{Mbps}$ \\
\hline The difference & \multicolumn{2}{|l|}{} \\
\hline $\mathbf{3 0} \mathbf{M H z}$ & 120.9 \\
\hline normal cyclic prefix & 104.3 \\
\hline Extended cyclic prefix & $16.6 \mathrm{Mbps}$ \\
\hline The difference & 141.1 \\
\hline $\mathbf{3 5}$ MHz & 121.7 \\
\hline normal cyclic prefix & $19.4 \mathrm{Mbps}$ \\
\hline Extended cyclic prefix & \\
\hline The difference (in $\mathbf{M b p s})$ & 161.3 \\
\hline $\mathbf{4 0}$ MHz & 139.1 \\
\hline normal cyclic prefix & $22.2 \mathrm{Mbps}$ \\
\hline Extended cyclic prefix & \\
\hline The difference & 403.1 \\
\hline $\mathbf{1 0 0}$ MHz & 347.8 \\
\hline normal cyclic prefix & $55.3 \mathrm{Mbps}$ \\
\hline Extended cyclic prefix & \\
\hline The difference &
\end{tabular}

\section{Conclusion}

The study results show that SNR improvement increase the capacity and the analysis show that numerical values of capacity in Mbps for normal cyclic prefix is highest than capacity in extended cyclic prefix for LTE downlink in all transmission bandwidths $(25,30,35,40$ and 100) $\mathrm{MHz}$.

This demonstrates that use the extended cyclic prefix decreases the system capacity because it has longer cyclic prefix duration than the normal cyclic prefix case.

\section{References}

[1] M. Kottkamp, A. Roessler, J. Schlienz, "LTE-Advanced Technology Introduction", Rohde \& Schwarz LTE Advanced Technology Introduction 3, 2012

Volume 5 Issue 6, June 2016 www.ijsr.net

Licensed Under Creative Commons Attribution CC BY 
[2] www.lte-bullets.com, " long term evolution (LTE) cyclic prefix"

[3] Tetsushi abe, ntt docomo vice-chairman 3gpp tsg ran wg1, "LTE radio physical layer", 3gpp work shop 2010.

[4] C.E. Shannon, R.G. Gallager, and E.R. Berlekamp, "Lower bounds to error probabilities for coding on discrete memoryless channels" Inform. Contr., vol. 10, 1967

[5] Christian Mehlfuhrer, Martin Wrulich, Josep Colom Ikuno, Dagmar Bosanska, Markus Rupp, "SIMULATING THE LONG TERM EVOLUTION PHYSICAL LAYER" Institute of Communications and Radio-Frequency Engineering Vienna University of Technology, 17th European Signal Processing Conference (EUSIPCO 2009) PP Workshop 2 June, 2010, Chennai 3GPP Workshop 2 June, 2010.

\section{Author Profile}

Emad aldeen Abd Allah Omer received the B. Sc degrees in Electrical Engineering computer Engineering specialize from alzaiem Alazhary University in 2009 and attended for M.S.c degree in Data and Communication Network in Alneelain University and in 2014.

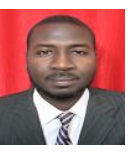

Mohammed Abaker Hussian Adam, Doctor of Philosophy $(\mathrm{PhD})$ in Electric and Electronic Engineering (Communications), University of AL Neelain, Sudan 2015. Master of Science (MSc) in Electric and Electronic Engineering (Telecommunication and Information Systems) University of Khartoum, Sudan, 2007. (Bsc). (honor) of Electronic engineering(Communication) University of AL Neelain, Sudan, September 2002 